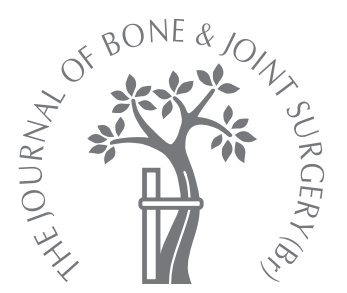

S. Konan,

F. Rayan,

F. S. Haddad

From University

College London

Hospitals, London,

England

\title{
Is the frog lateral plain radiograph a reliable predictor of the alpha angle in femoroacetabular impingement?
}

The radiological evaluation of the anterolateral femoral head is an essential tool for the assessment of the cam type of femoroacetabular impingement. CT, MRI and frog lateral plain radiographs have all been suggested as imaging options for this type of lesion. The alpha angle is accepted as a reliable indicator of the cam type of impingement and may also be used as an assessment for the successful operative correction of the cam lesion.

We studied the alpha angles of 32 consecutive patients with femoroacetabular impingement. The angle measured on frog lateral radiographs using templating tools was compared with that measured on CT scans in order to assess the reliability of the frog lateral view in analysing the alpha angle in cam impingement.

A high interobserver reliability was noted for the assessment of the alpha angle on the frog lateral view with an intraclass correlation coefficient of 0.83 . The mean alpha angle measured on the frog lateral view was $58.71^{\circ}\left(32^{\circ}\right.$ to $\left.83.3^{\circ}\right)$ and that by CT was $65.11^{\circ}\left(30^{\circ}\right.$ to $\left.102^{\circ}\right)$. A poor intraclass correlation coefficient $(0.08)$ was noted between the measurements using the two systems.

The frog lateral plain radiograph is not reliable for measuring the alpha angle. Various factors may be responsible for this such as the projection of the radiograph, the positioning of the patient and the quality of the image. CT may be necessary for accurate measurement of the alpha angle.

Femoroacetabular impingement (FAI) may cause early osteoarthritis of the hip. ${ }^{1-6}$ The damage to the articular cartilage is caused by two forms of impingement, cam and pincer or a combination of both. ${ }^{1,2}$ In cam FAI there is an aspherical cartilage-bearing area at the femoral head-neck junction which is the result of a relative prominence of the head or a reduced headneck offset at the anterolateral head-neck junction. By contrast pincer FAI is due to excessive cover of the femoral head. ${ }^{7}$ The three methods of assessing this disorder are conventional plain radiographs, MRI and CT. Most studies have relied on imaging rather than on clinical evaluation. Beaule et $\mathrm{al}^{8}$ concluded that the femoralhead concavity can be measured accurately by CT. The bony outlines can be identified clearly on plain radiographs and the frog lateral view allows accurate visualisation of the femoralhead offset ${ }^{9}$ while MRI can be used to investigate labral and chondral lesions. ${ }^{10-12} \mathrm{~A}$ recent study by Pfirrmann et $\mathrm{al}^{13}$ showed that radial slices are required to identify the asphericity of the head-neck junction and to establish the diagnosis of cam FAI in modest deformities which cannot be seen on plain radiographs.
The alpha angle as a measurement of the sphericity of the femoral head is a reliable indicator of cam $\mathrm{FAI}^{14}$ and it may be used in association with the triangular index. ${ }^{15}$ The alpha angle may also be used to assess operative correction of the cam lesion.

Our aim was to assess the reliability of the measurement of the alpha angle using frog lateral plain radiographs as a simple radiological tool for the diagnosis of FAI.

\section{Patients and Methods}

We reviewed the radiographs and CT scans of a consecutive series of 32 patients between February 2007 and August 2007 treated for cam-type FAI. All the patients (32 hips) had been treated by arthroscopy and osteoplasty of the hip with or without debridement of a labral tear, by a single surgeon (FSH). The diagnosis of FAI was based on the clinical history, physical examination, radiological imaging and hip arthroscopy. All the patients had pain in the groin, a positive impingement test in which pain was elicited on passive flexion, adduction, and internal rotation of the hip and radiological evidence of an abnormal prominence or reduced offset at the femoral head-neck junction. 


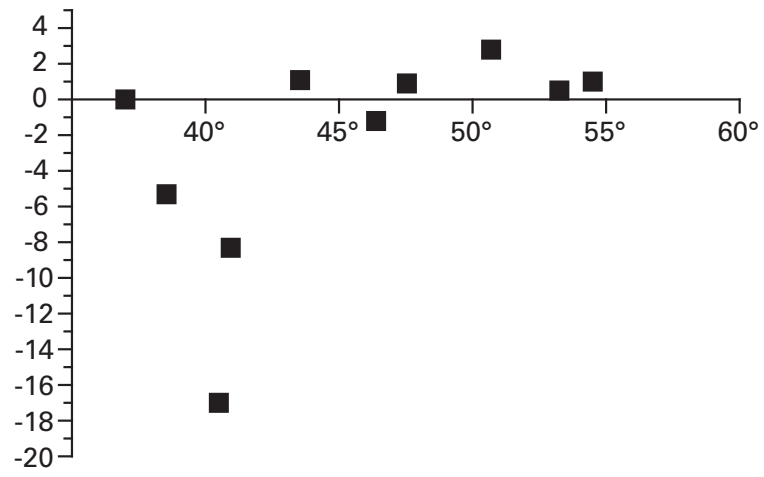

Fig. 1

Bland-Altman plot of interobserver variability of the alpha angle measured on a plain frog-lateral radiograph. The $\mathrm{x}$-axis plots the mean angle $\left({ }^{\circ}\right)$ against the difference (observer 1 and observer 2 ) on the $y$-axis.

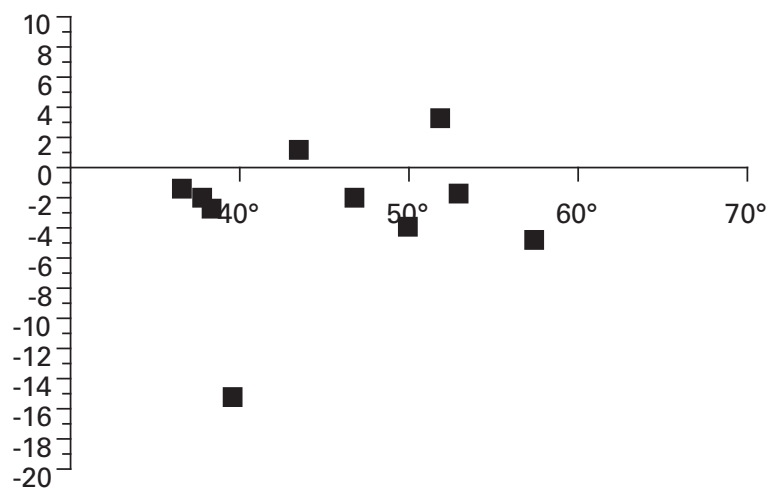

Fig. 2

Bland-Altman plot of intraobserver variability of the alpha angle measured on a plain frog-lateral radiograph. The $\mathrm{x}$-axis plots the mean angle $\left({ }^{\circ}\right)$ against the difference (reading 1 and reading 2 ) on the $y$-axis.
There were 14 women and 18 men with a mean age of 32 years (22 to 46). All had standard radiographs including an anteroposterior (AP) view of the pelvis and a frog-lateral view of the affected hip. For both views, the $\mathrm{x}$-ray tube was positioned approximately $100 \mathrm{~cm}$ from the frontal plane of the film cassette.

A standardised technique was used for radiography. For the $\mathrm{AP}$ view, patients were instructed to stand upright with both feet one shoulder's width apart with the knees facing forwards. The x-ray beam was centred on the symphysis pubis in the vertical midline and the field included both iliac crests.

For the frog lateral view the patient was positioned supine on the x-ray table and the ipsilateral knee was flexed so that the foot contacted the contralateral knee. The thigh was adbucted and externally rotated while ensuring that the plane of the pelvis was parallel to the plane of the table. The $\mathrm{x}$-ray beam was directed anterior to posterior and centred on the femoral head.

One independent observer (SK) made all the radiological measurements. In order to establish reliability two observers independently reviewed ten radiographs. The first reviewer also made measurements on two separate occasions, with the films provided in a random order and four weeks apart, in order to assess intraobserver reliability. Two measurements were made on each view, namely, the sphericity of the femoral head and the alpha angle.

All the measurements were made on digitally stored images on a Picture Archiving and Communications System (PACS) using the Impax orthopaedic templating system (Agfa HealthCare system, Mortsel, Belgium). The sphericity and the centre of the femoral head were determined using a circular template interpolated from three reference points on the femoral head. If an anterolateral prominence was seen at the head-neck junction outside the circle and extended in a convex shape to the base of the neck, it was considered to be aspherical.
The alpha angle was measured according to the method described by Nötzli et al. ${ }^{14} \mathrm{~A}$ line was drawn through the longitudinal axis of the femoral neck between the centre of the femoral head and the centre of the femoral neck at its narrowest point. Next, the anterior extent of the concavity of the femoral neck was determined using the circular reference described above. A point was marked where the radius of curvature of the femoral head first deviated from the circular template. A straight line was connected from this point to the centre of the femoral head. The angle measured between this line and the longitudinal axis of the femoral neck represented the alpha angle.

The intra- and interobserver reliabilities ${ }^{16}$ for the measurements of the alpha angle were assessed using the intraclass correlation coefficient which was interpreted using the following thresholds: $<0.40$, slight agreement; 0.41 to 0.70 , moderate agreement; and $>0.70$ good agreement.

The kappa coefficient was used for gauging the reliability of the sphericity of the head applying the same thresholds of agreement used for the intraclass correlation coefficient.

The alpha angle measured on the plain radiographs was then compared with that calculated using threedimensional (3D) reconstruction CT. Hips were scanned with the patients supine by a helical technique with collimation of $3 \mathrm{~mm}$ and a reconstruction interval of $2 \mathrm{~mm}$ using a Siemens Sensation 64 high-speed CT scanner (Siemens, Erlangen, Germany). The 3D reconstructions were performed on the Siemens Sensation 64 graphics workstation.

The CT scans were also studied for inter- and intraobserver variability using similar methods as used for the plain radiographs. All the recordings established a high reliability. 


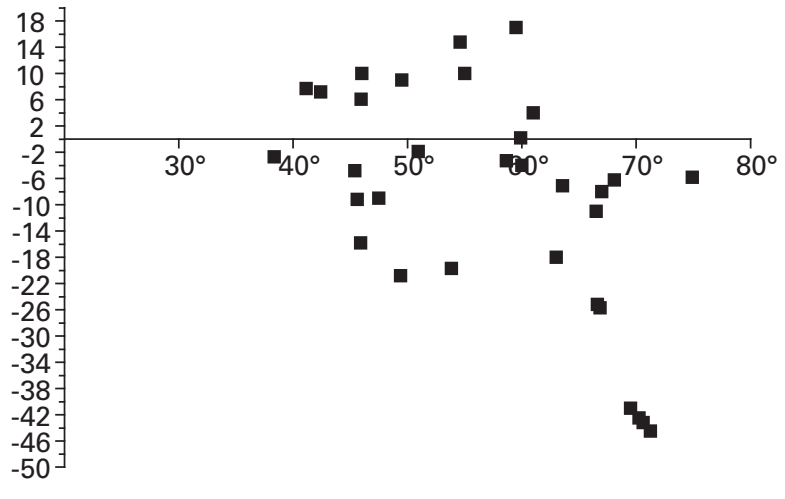

Fig. 3

Bland-Altman plot of the difference in the alpha angle (CT and radiograph) against the mean alpha angle. The $x$-axis plots the mean angle $\left({ }^{\circ}\right)$ against the difference (CT and radiograph) on the y-axis.

In order to simplify the presentation of results, the difference between the alpha angles measured on plain radiographs and CT scans was arbitrarily divided into three groups as follows: $<5^{\circ}$ difference; $5^{\circ}$ to $10^{\circ}$ difference and greater than $10^{\circ}$ difference.

Statistical analysis. The reproducibility of the alpha angles measured on plain radiography and 3D CT was statistically analysed using the intraclass correlation coefficient. A paired $t$-test was performed to assess bias in the reliability studies comparing the measurement of the alpha angle by $\mathrm{CT}$ and plain radiography. A p-value of $\leq 0.05$ was considered to be statistically significant.

To illustrate the difference in the measurement of the alpha angle using the two methods, a Bland-Altman plot of the difference (CT to radiograph) between measurement of the alpha angle was plotted against the mean.

\section{Results}

The кappa analysis of reliability for assessing the sphericity of the femoral head on a frog lateral plain radiograph showed moderate agreement with a coefficient of 0.57 (95\% confidence interval (CI) 0.48 to 0.71 ).

A high interobserver reliability was noted for the assessment of the alpha angle on a frog lateral view with an intraclass correlation coefficient of 0.83 (95\% CI 0.69 to 0.89 ). The intraobserver reliability was also noted to be high with an intraclass correlation coefficient of 0.88 (95\% CI 0.71 to 0.9$)$. The Bland-Altman plot of interand intraobserver reliability, respectively, of measurements of the alpha angle made on plain radiographs is shown in Figures 1 and 2. The 95\% limits of agreement of the interobserver reliability on a plain radiograph ranged from -14.48 to 9.38 (British Standards Reproducibility coefficient 12.17) and those of the intraobserver reliability on a plain radiograph from -12.56 to 6.69 (British Standards Reproducibility coefficient 9.8). From the graphs it is noted than there is a poorer agreement for smaller measurements suggesting possible bias.
The mean alpha angle measured on a frog lateral view was $58.71^{\circ}\left(32^{\circ}\right.$ to $\left.83.3^{\circ}\right)$. The mean alpha angle measured on a CT scan was $65.11^{\circ}\left(30^{\circ}\right.$ to $\left.102^{\circ}\right)$. The difference between the alpha angle measured on a plain radiograph and on a CT scan was within $5^{\circ}$ in $11(33 \%)$ cases, between $5^{\circ}$ to $10^{\circ}$ in nine $(29 \%)$ cases and $>10^{\circ}$ in $12(38 \%)$. Plain radiographs overestimated the alpha angle in $18(57 \%)$ of cases and underestimated it in 14 $(43 \%)$. There was no significant correlation between measurement of the alpha angle by CT or by radiography (paired $t$-test, $\mathrm{p}=0.67$ ), suggesting that there was no evidence of bias.

The Bland-Altman plot (Fig. 3) illustrated a wide variation between the measurement of the alpha angle made on plain radiographs. The $95 \%$ limits of agreement between measurements by CT and by plain radiographs ranged from $-42.25^{\circ}$ to $24.54^{\circ}$ (British Standards Reproducibility coefficient 34.08 ).

A poor intraclass correlation coefficient $(0.08,95 \%$ CI -0.35 to 0.47$)$ was noted between measurement of the alpha angle using the two imaging systems.

\section{Discussion}

An accurate radiological evaluation is critical for diagnosis and surgical decision-making in FAI. Beall et $\mathrm{al}^{17}$ summarised the imaging abnormalities using three different methods in FAI. In conventional radiography, AP and lateral views are used. On the AP view the most characteristic feature of cam FAI is the bony abnormality which has been described as a pistol-grip deformity. ${ }^{17}$ Head-neck offset is delineated by lateral views. Clohisy et $\mathrm{al}^{9}$ compared three radiological techniques (frog lateral, cross-table lateral and AP) and concluded that the frog lateral radiograph was the best predictor of femoral head-neck offset in patients with FAI. Plain radiographs can easily detect bony deformities and synovial herniation pits which are indicative of FAI. ${ }^{17}$ Eiker, Myers and Ganz ${ }^{18}$ suggested that the head-neck offset should be measured on the cross-table lateral radiograph of the hip. Meyer et $\mathrm{al}^{19}$ recently compared six different views on cadaver femora and concluded that the Dunn $45^{\circ}$ projection was best for visualising the prominence at the anterolateral head-neck junction as the hip is projected in less abduction and less external rotation. The study was based solely on the magnitude of the alpha angle, but no comparisons were made between impingement specimens and control specimens to determine the difference between the groups.

MRI is useful for detecting labral and chondral damage. ${ }^{13,20}$ Labral lesions are associated with pincer $\mathrm{FAI},{ }^{13}$ but cartilage damage may also result from FAI. ${ }^{17}$ This is seen in cam FAI at the anterosuperior position and in pincer lesions at the posteroinferior position. ${ }^{13}$ MRI is useful for determining the alpha angle and can be used to measure the sphericity of the femoral head ${ }^{21}$ as well as to determine the head-neck ratio. ${ }^{14}$ Nötzli et al ${ }^{14}$ used MRI to measure the alpha angle in 39 patients and 35 control subjects reporting 
mean values of $74^{\circ}$ and $42^{\circ}$, respectively. It was concluded that all patients with impingement had an alpha angle of more than $55^{\circ} .{ }^{14}$ This could have been due to a wide femoral neck, osteophytes, abnormality of growth or posterior displacement of the femoral head. ${ }^{7,21}$ Leunig et $\mathrm{al}^{5}$ compared patients affected with FAI with those who had developmental dysplasia and showed that MRI could distinguish these two disorders. ${ }^{10}$ James et $\mathrm{al}^{11}$ compared the MRI findings with the surgical outcome. All labral tears diagnosed by MRI were confirmed surgically and $92 \%$ of labral lesions and $89 \%$ to $94 \%$ of acetabular chondral lesions noted intra-operatively were diagnosed correctly by preoperative MRI. By contrast, Schmid et $\mathrm{al}^{20}$ reported that MRI imaging was not effective because of the relatively thin cartilage. Recently, it has been reported that the extent of cartilage damage noted per-operatively was greater than that seen on MRI. Newer imaging techniques for cartilage such as delayed gadolinium-enhanced MRI may give more diagnostic accuracy. ${ }^{22}$

CT is a good diagnostic tool since it allows the measurement of the alpha angle and head-neck ratio to be made. Philippon et $\mathrm{al}^{23}$ reported that CT was useful in the pre-operative mapping of the acetabular rim and the headneck junction. Beaulé et $\mathrm{al}^{8}$ compared the alpha angle using 3D CT and found this to be an accurate tool for quantifying head-neck concavity.

We conclude that the ideal imaging modality for the diagnosis of FAI is debatable. Plain radiography is costeffective and readily available. It is generally used as the screening tool. However, variations in radiological technique, projection of the $\mathrm{x}$-ray beam, and patient characteristics can influence its accuracy. Imaging by CT may be essential for the accurate pre-operative and post-operative measurement of cam lesions.

No benefits in any form have been received or will be received from a commercial party related directly or indirectly to the subject of this article.

\section{References}

1. Beck M, Kalhor M, Leunig M, Ganz R. Hip morphology influences the pattern of damage to the acetabular cartilage: femoroacetabular impingement as a cause of early osteoarthritis of the hip. J Bone Joint Surg [Br] 2005;87-B:1012-18.

2. Ganz R, Parvizi J, Beck M, et al. Femoroacetabular impingment: a cause for osteoarthritis of the hip. Clin Orthop 2003;417:112-20.
3. Ito K, Minka MA 2nd, Leunig M, Werlen S, Ganz R. Femoroacetabular impingement and the cam-effect: a MRI-based quantitive anatomical study of the femoral head-neck offset. J Bone Joint Surg [Br] 2001;83-B:171-6.

4. Leunig $\mathbf{M}$, Beck $\mathbf{M}$, Kalhor $\mathbf{M}$ et al. Fibrocystic changes at anterosuperior femoral neck: prevalence in hips with femoroacetabular impingement. Radiology 2005;236:237-46.

5. Leunig M, Beck M, Woo A, et al. Acetabular rim degeneration: a constant finding in the aged hip. Clin Orthop 2003;413:201-7.

6. Bardakos NV, Villar RN. Predictors of progression of osteoarthritis in femoroacetabular impingement: a radiological study with a minimum of ten years follow-up. $J$ Bone Joint Surg [Br] 2009;91-B:162-9.

7. Siebenrock KA, Wahab KH, Welen S, et al. Abnormal extension of the femoral head epiphysis as a cause of cam impingement. Clin Orthop 2004;418:54-60.

8. Beaulé PE, Zaragoza E, Motamedi K, Copelan N, Dorey FJ. Three-dimensional computed tomography of the hip in the assessment of femoroacetabular impingement. J Orthop Res 2005;23:1286-92.

9. Clohisy JC, Nunley RM, Otto RJ, Schoenecker PL. The frog-leg lateral radiograph accurately visualized hip cam impingement abnormalities. Clin Orthop 2007;462:115-21

10. Leunig M, Podeszwa D, Beck M, Werlen S, Ganz R. Magnetic resonance arthrography of labral disorders in hips with dysplasia and impingement. Clin Orthop 2004:418:74-80.

11. James SL, Ali K, Malara F, et al. MRl findings of femoroacetabular impingement. AJR Am J Roentgenol 2006; 187:1412-19.

12. Kubo T, Horii M, Harada $\mathbf{Y}$, et al. Radial-sequence magnetic resonance imaging in evaluation of acetabular labrum. J Orthop Sci 1999;4:328-32.

13. Pfirrmann CW, Mengiardi B, Dora C, et al. Cam and pincer femoroacetabular impingement: characteristic MR arthrographic findings in 50 patients. Radiology 2006;240:778-85

14. Nötzli HP, Wyss TF, Stoecklin CH, et al. The contour of the femoral head-neck junction as a predictor for the risk of anterior impingement. J Bone Joint Surg $[\mathrm{Br}]$ 2002;84-B:556-60.

15. Gosvig KK, Jacobsen S, Palm H, Sonne-Holm S, Magnusson E. A new radiological index for assessing asphericity of the femoral head in cam impingement. $J$ Bone Joint Surg [Br] 2007;89-B:1309-6.

16. Landis JR, Koch GG. The measurement of observer agreement for categorical data. Biometrics 1977;33:159-74.

17. Beall DP, Sweet CF, Martin HD, et al. Imaging findings of femoroacetabular impingement syndrome. Skeletal Radiol 2005;34:691-701.

18. Eiker H, Myers SR, Ganz R. Anterior femoroacetabular impingement after femoral neck fractures. J Orthop Trauma 2001;15:475-81.

19. Meyer DC, Beck M, Ellis T, Ganz R, Leunig M. Comparison of six radiographic projections to assess femoral head/neck asphericity. Clin Orthop 2006;445:181-5.

20. Schmid MR, Nötzli HP, Zanetti M, Wyss TF, Hodler J. Cartilage lesions in the hip: diagnostic effectiveness of MR arthrography. Radiology 2003; 226:382-6.

21. Kassarjian A, Brisson M, Palmer WE. Femoroacetabular impingement. Eur $J$ Radiol 2007;63:29-35.

22. Peters CL, Erickson JA. Treatment of femoro-acetabular impingement with surgical dislocation and debridement in young adults. J Bone Joint Surg [Am] 2006;88A:1735-41.

23. Philippon MJ, Stubbs AJ, Schenker ML, et al. Arthroscopic management of femoroacetabular impingement: osteoplasty technique and literature review. $\mathrm{Am} J$ Sports Med 2007;35:1571-80. 